\title{
Attendance Monitoring Model for Range Surveillance Using Bluetooth
}

\author{
Shashidhar Honnalli, Golla Vara Prasad \\ Department of Computer Science and Engineering, B. M. S. College of Engineering, Bengaluru, India
}

Email address:

gvara@rediff.com.com (S. Honnalli),drgvpphd@gmail.com (G. V. Prasad)

\section{To cite this article:}

Shashidhar Honnalli, Golla Vara Prasad. Attendance Monitoring Model for Range Surveillance Using Bluetooth. International Journal of Sensors and Sensor Networks. Vol. 7, No. 4, 2019, pp. 56-61. doi: 10.11648/j.ijssn.20190704.12

Received: September 7, 2019; Accepted: January 3, 2020; Published: February 13, 2020

\begin{abstract}
Internet of Thing (IOT) has applications used in enormous fields such as automation of home appliances, medical aids, smart waste management, mobile, health care, traffic management, smart city, attendance, etc. The goal of this work is to propose a smart attendance system, which can be used to obtain the attendance of students. Attendance system is described in systematic approach, where students enter the classroom with a mobile device during the scheduled time. Nowadays, teachers in Colleges and Universities will collect the attendance details by calling out name or by-passing attendance sheet for individual student signature to authorize his/her presence. Mentioned approaches take lot of time to get the attendance details. Hence, approach for taking attendance using Bluetooth module has been proposed, which takes less time and this method gives an accurate result. Here, Bluetooth module and Arduino are interconnected and the Arduino board is connected with laptop or PC by using USB cable. Initially, MAC addresses of students Bluetooth cell phones are enabled and collected and stored in the database. Bluetooth module scans the student's mobile's Bluetooth with help of MAC address, which is unique with respect to each mobile phone. A Bluetooth module scans the MAC addresses of student's mobile phone, which is connected to the Arduino and compares with data base and confirms the presence of the student. Likewise, complete attendance is recorded in a document and this is mailed to the lecturer.
\end{abstract}

Keywords: MAC Address, Arduino, Bluetooth Module

\section{Introduction}

Internet of Things (IoT) is a trending technology in recent days and tries to explain that each physical object contains a different address that will be unique with respect to each object. It will be used to interact with other physical objects over the internet and uses embedded technology. IoT has a lot of advantages in various fields such as home automation, medical aids, smart waste control, cellular, healthcare, smart city, attendance system etc.

Attendance is taken in each single Institute or College. System includes a procedure that is performed manually by the teachers and the recorded attendance is saved within the sign-up or on attendance sheets that are dealt by the instructor, therefore college students no longer have any access to the information. Absentee list is formed using saved records, the calculations required are manually carried out by staff. The calculations done by staff may result in human mistakes and they have to be maintained for the entire duration of the semester, which introduces the load of document preserving. Student attendance system is a project, based on Arduino, mobile and Bluetooth software. This system is developed to take the student attendance during lecture hour as the students enter the lecture hall or laboratory. Bluetooth module scans the Bluetooth MAC addresses of nearby cell phones and compares it with database. If the MAC addresses obtained from scanning process matches with the database, then student is marked as present and the text will be created and the mail attached with text file is sent to the particular lecturer based on the timetable. This work has a lot of advantages such as low cost and low power consumption and provides an accurate result.

\section{Related Work}

Survey on various methods of attendance systems were made. Existing student attendance systems are fingerprint based attendance system, face recognition based attendance 
system and RFID based attendance system and GPS based attendance system etc. In fingerprint based attendance system, student entering the class has to scan his finger in fingerprint scanner, which is fixed at the classroom and in face recognition attendance system, at the entry point of a classroom a CCTV camera is fixed, which robotically takes image of each person and here the attendance is recorded using Face recognition. In RFID based attendance system, the student must keep their ID card close to the RFID reader, which is then compared with the database and marks the attendance.

In paper [1] system contains a camera, which is to be fixed at the entry point of the lecture hall and they have PC installed with MATLAB and the camera is connected to PC. The system has some methodologies those are creating face database, video recording, face detection, face recognition, registering attendance. Initially, face database has been created, which contains the pictures of each enrolled students. The pictures will be focused only on the face region. The camera, which is fixed at the entry point of the classroom records video, which has to be used in face detection process. After recording, individual student's face will be detected and cropped for further process. They have used "vision. CascadeObjectDetector" command to detect faces, which is an inbuilt function in MATLAB and this command is used for comparison. In face recognition process, the cropped faces are compared with the previously stored face database using algorithms [15-16] LDA and [914] PCA and if both the cropped faces are matched, then the attendance of individual student is marked in the excel sheet. The main drawback of the system is comparing of stored face database and recognized face database take more time and face recognition is not effective in low light.

In paper [2] system is to detect his/her presence in the educational institute. Here, they have used RFID technology to detect the presence of the employee or student. The RFID tags have been issued to the all the employees or students of the organization. The RFID tag has the information about identification number and it also contains personal details of the user, which has been collected initially. To secure the information they have used the high-security system. In their system, they have interconnected Arduino, SD card and the RFID reader. They also used the real-time clock to know when user gives attendance. While student or employees entering the organization should scan his/her tag against RFID reader and it stores the information and if the scanned details and previously store details are matched, the attendance will be marked. Finally, the complete data will be stored in the SD card. Later, the attendance is updated on the Thing speak account. The drawback of this work is, verification is not done. So, proxy attendance may be marked and time-consuming.

In paper [3] system contains GPS to mark the attendance and they have used the mobile application to register student or employee, that application is used for studnets login and helps to locate the students. The students can be informed regularly about their attendance by the admin when they log in and log out of the application, so that the students can keep track of attendance details by using the application. Using GPS of the mobile phone, the location of any student's latitude, longitude, and IMSI number can be tracked by the admin. The student's current position within the geographical location can be tracked by using GPS enabled mobile phone and application. The student presence in the classroom is tracked by using Google map within the geographical location. This system has a drawback where the, schedule of the location of a class may change any time and in that time, proxy attendance can be marked and the chances of giving proxy are more.

In paper [4] system contains NFC devices, which are connected to the server PC, thus the data will be stored in a single database on server PC. The students/instructors have given NFC device, which is used for student identification. NFC readers scan the id of each student's NFC tag, alternatively embedded camera device on mobile phone captures the photos for verification. Otherwise, if student gives his/her NFC tag to a classmate, who will attend the lecture, proxy attendance can be marked. Proxy attendance of students can be avoided by using the above-mentioned verification process i.e. by capturing photos using embedded camera device on a mobile phone. After the verification process, if id and the collected picture of the student matches, then the attendance will be marked as present and the attendance details are sent to the server. This method has drawbacks of small range, max range 10 to $20 \mathrm{~cm}$. Also, the cost of installation setup is more.

In paper [5] attendance system is monitored using finger recognition technique. The system shows the time and reads the SD card. Initially, the fingerprints of each person must be collected [6-10]. The person or student, while entering into the lecture hall, the process of scanning fingerprints is started for recording the attendance of students, if the scanned fingerprint matches with the previously collected fingerprint database, then the student id number will be displayed on the device and saves the attendance details in the SD card. If the fingerprint does not match with the fingerprint in a database system, then the device informs the user about the wrong fingerprint. The system contains Arduino and SD card, which are used to store and compare the database. The main drawback of the system is, fingerprint scanning device may get damaged very frequently and also while scanning finger on the fingerprint device, the student has to stand in long line for marking attendance [11-12].

\section{Proposed System}

Figure 1 shows the system architecture of student attendance system, which consists of Bluetooth module, Arduino board, and laptop. Initially, the database consisting of MAC address of each student's Bluetooth enabled cell phone is created. Then Arduino is interfaced with the HC-05 Bluetooth module and using this Bluetooth MAC address of nearby cell phones are scanned and compared with the database. 


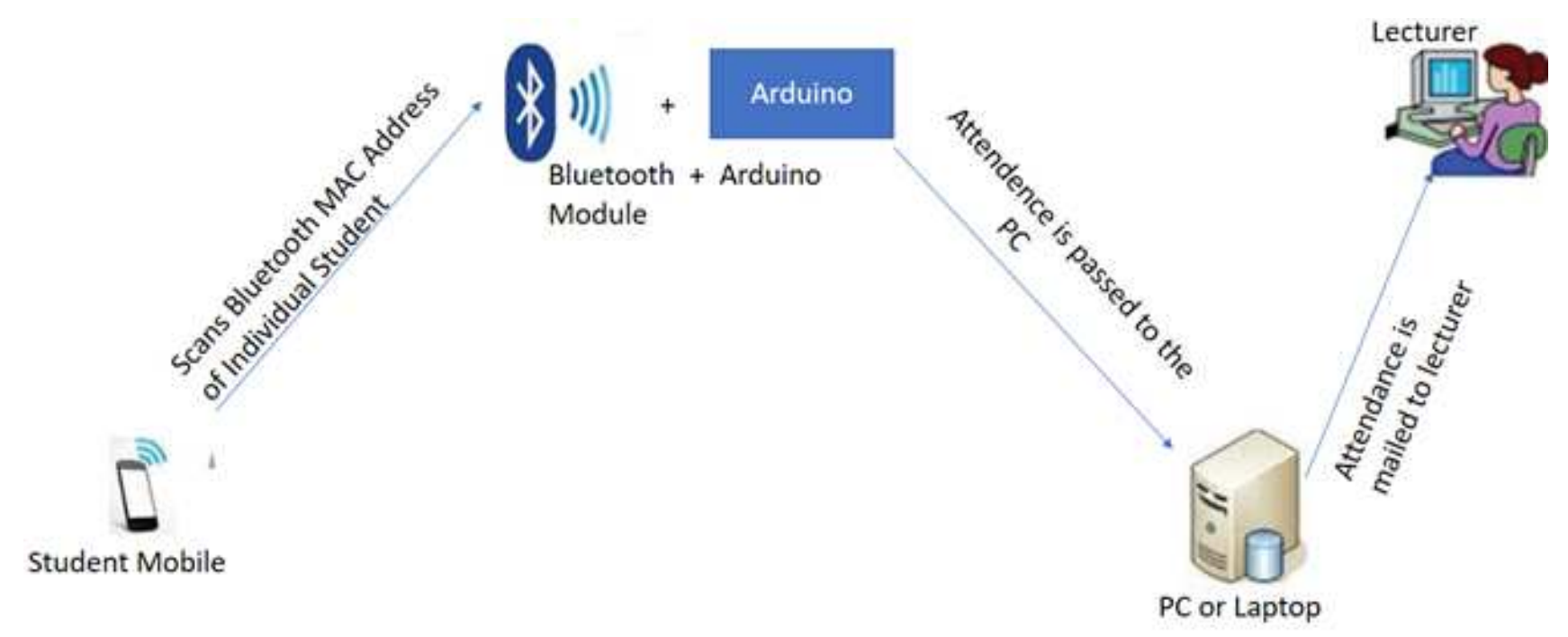

Figure 1. System architecture.

The scanning process will be continued until the time out of a specified timer. If the MAC addresses obtained by scanning process matches with the database, text file containing student names will be created and mail attached with text file will be sent to the lecturer based on timetable.

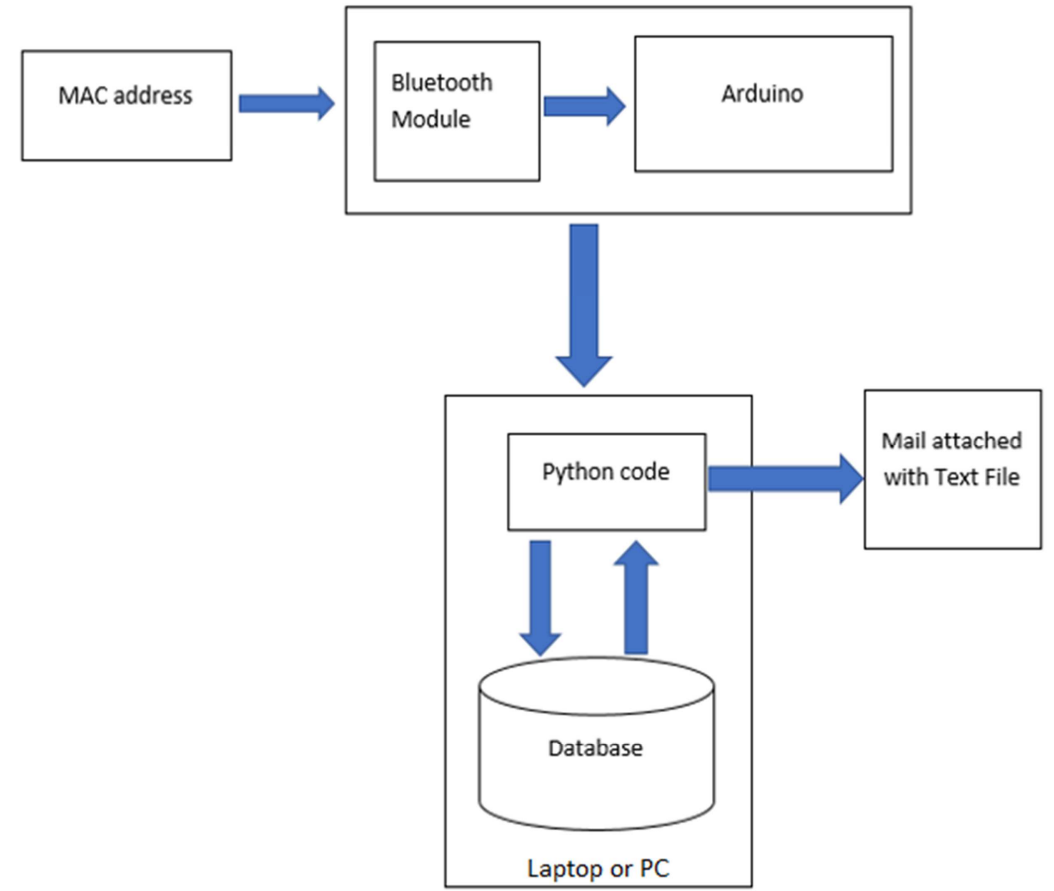

Figure 2. Overall system design.

Figure 2 depicts the overall system design of Bluetooth based student attendance system. This system is used to extract the attendance of individual student using Bluetooth module. In the overall system, the Bluetooth module and Arduino are interconnected and the Arduino is connected to the laptop or PC using USB cable and the power is supplied to the Arduino.

Initially, MAC addresses of students Bluetooth enabled cell phones is collected and stored in the database. The Bluetooth module scans the student's mobile's Bluetooth
MAC address, which is unique with respect to each mobile. After obtaining the student information, it will compare the MAC address with the database, if it matches with database, then respective student name is entered in text file created by python code, then this code runs for a specific time and keeps collecting the attendance of the students who are all present. Once the scanning and comparing process ends, python code sends the text file containing student names who are present in the class to the lecturer through email using python code. 


\section{Results and Discussion}

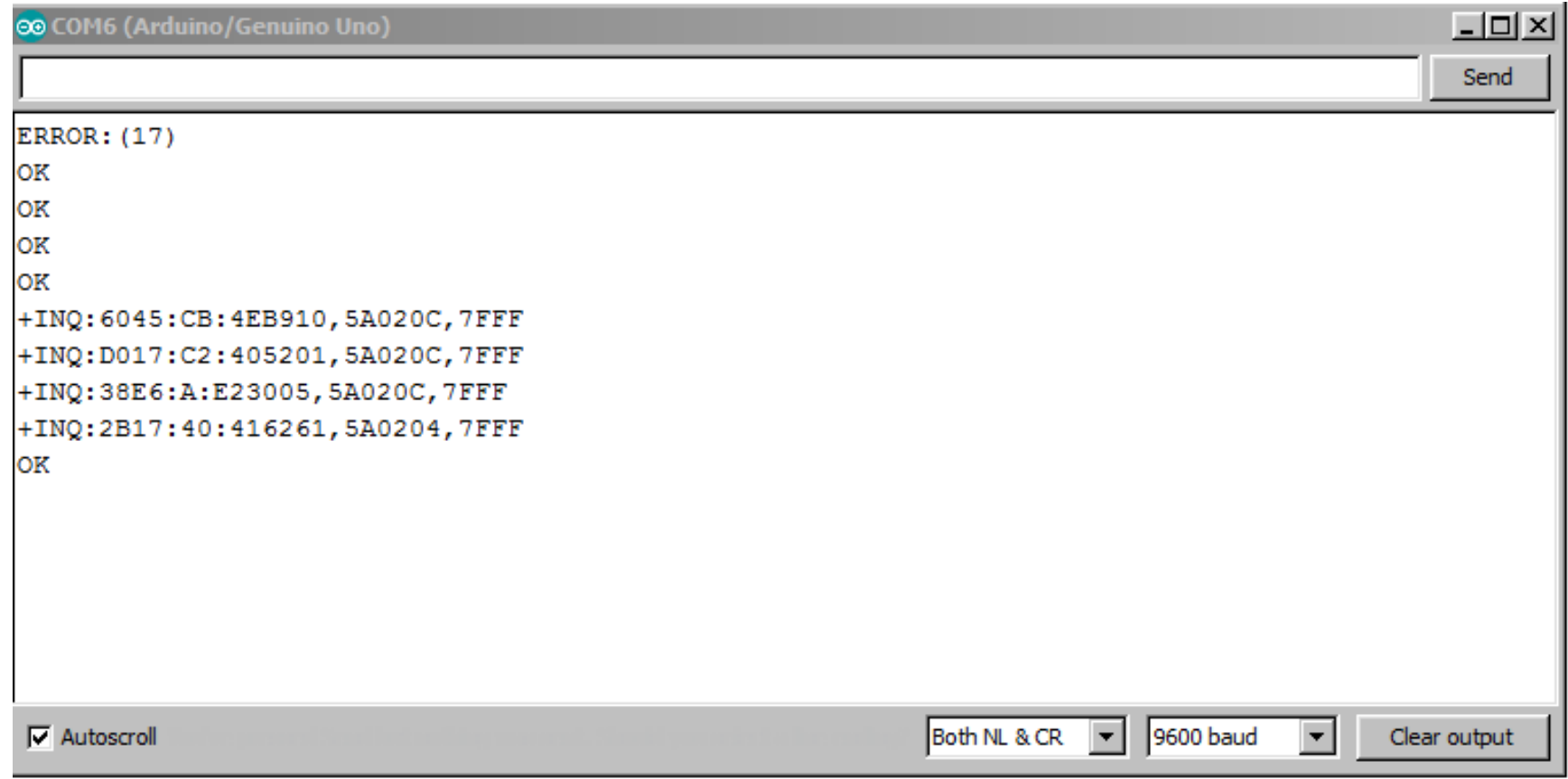

Figure 3. MAC addresses obtained after scanning.

Bluetooth module connected to Arduino will scan the MAC addresses of Bluetooth enabled students' mobile phones, who are present in the class. After scanning results obtained are as shown in figure 3.

\section{COMPOSE}

Inbox $(6,001)$

Starred

Important

Sent Mail

Drafts (4)

- Categories

Personal

Travel

\section{Attendance $\square \quad$ Inbox $x$}

shashipreetam28@gmail.com

to me $\nabla$

ATTENDANCE

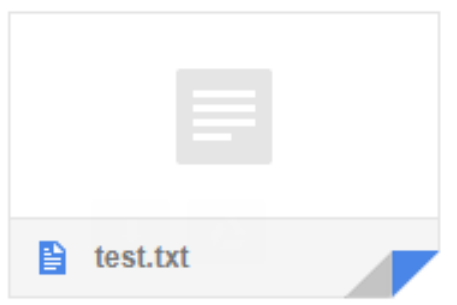

Figure 4. Mail attached with text file.

A mail attached with text file containing attendance details of students is sent to the particular lecturer, based on the time table is as shown in figure 4. 


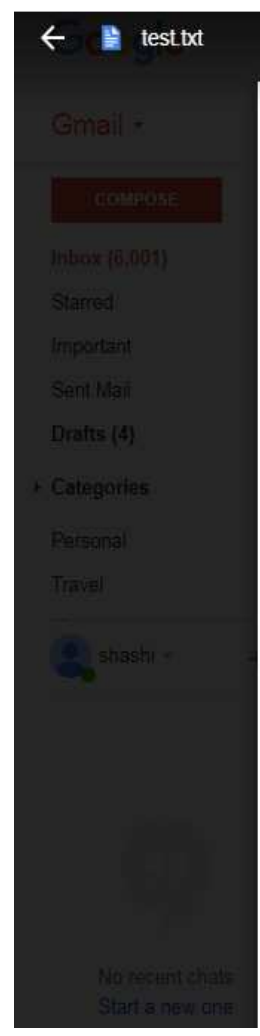

Figure 5. Attendance list of students present in the class.

Attendance of each student is sent to the lecturer is in the form of text file, which contains students' names who are present in the class, time and date of that class is as shown in figure 5 .

\section{Conclusion}

Through this work, a new technology for student attendance and surveillance system, based on Bluetooth low energy module and Arduino has been implemented. Bluetooth module has been used to scan the MAC addresses of student's mobile phone. It is connected to the Arduino board and scanned-MAC address is compared with the database. If both MAC addresses are matched, then it confirms the presence of student in the classroom and student attendance details are mailed to the lecturer based on the timetable. The proposed system is useful for both, students and lecturers in terms of utilization of time as well as cost. It seems to be a good choice in near future to meet the developing necessities of the technology in an effective manner.

\section{References}

[1] Anshun Raghuwanshi, Preeti D Swami, "An Automated Classroom Attendance System using Video based Face Recognition", In Proceedings of Recent Trends in Electronics, Information and Comunication Technology (RTEICT), International Conference 2017, pp. 719-724.

[2] Hasan U. Zaman, Jannatul Siffat Hossain, Tasnim Tamanna Anika, Deboshree Choudhury, "RFID based Attendance
System", In Proceedings of International Conference on Computing, Communication and Networking Technologies (ICCCNT), 2017, pp. 1-5.

[3] G Varaprasad, "High stable power aware multicast algorithm for mobile ad hoc networks", IEEE Sensors Journal 13, (5), $1442-1446$

[4] B Sivakumar, G Varaprasad, "Identification of critical node for the efficient performance in MANET", Editorial Preface, Vol. 3, No. 1, pp. 20-25, 2012.

[5] G Varaprasad, Shiva G Murthy, Johny Jose, RJ D'Souza, "Design and development of efficient algorithm for mobile ad hoc networks using cache", Vol. 1, No. 2/3, pp. 183-188, 2011.

[6] Albert Mayan. J, Mohammed Yusuf Khan, Md. Sabeelur Rahman K, S. P. Avinaash Ram, "GPS enabled Employee Registration and Attendance Tracking System", In Proceedings of International Conference on Control, Instrumentation, Communication and Computational Technologies (ICCICCT), 2015, pp. 62-65.

[7] Puchong Subpratatsavee, Tanabat Promjun, Wichian Siriprom, Worasitti Sriboon, "Attendance System using NFC Technology and Embedded Camera" In Proceedings of International Conference on Information Science \& Applications (ICISA), 2014, pp. 1-4.

[8] P Vagdevi, Divya Nagaraj, Golla Vara Prasad, "Home: IOT based home automation using NFC", International Conference on IoT in Social, Mobile, Analytics and Cloud, pp. 861-865, 2017.

[9] Santhosh Hebbar, Golla Vara Prasad, "Automatic water supply system for plants by using wireless sensor network", International Conference on IoT in Social, Mobile, Analytics and Cloud, pp. 742-745, 2017 
[10] Jitendra Kumar, Vinay Rishiwal and Mohammad Izharul Ansari, "Quality of Service in Wireless Sensor Networks: Imperatives and Challenges, International Journal of Sensors, Wireless Communications and Control, 9 (4): 419-431, 2019

[11] Nabila Samouni, Abdelillah Jilbab and Ahmed Hammouch "A Critical Review on Recent Research on Reliable Communication for Wireless Body Area Network, International Journal of Sensors, Wireless Communications and Control, 9 (4): 432-442
[12] Nur Izzati Zainal, Khairul Azami Sidek, Teddy Surya Gunawan, Hasmah Mansor, and Mira Kartiwi, "Design and Development of Portable Classroom Attendance System based on Arduino and Fingerprint Biometric Technique", In Proceedings of International Conference on Information and Communication Technology for The Muslim World (ICT4M), 2014, pp. 1-4. 